\title{
A study of ultrasonic velocity and attenuation on polycrystalline Ni-Zn ferrites
}

\author{
S R MURTHY \\ Department of Physics, Osmania University, Hyderabad 500 007, India
}

MS received 19 July 2001

\begin{abstract}
Polycrystalline NiZn ferrites with different grain sizes (1.2 $\mu \mathrm{m}$ to $10 \cdot 2 \mu \mathrm{m})$ were prepared by the usual ceramic method. The magnetic properties were measured at room temperature. The ultrasonic velocity and attenuation were measured on $\mathrm{Ni}-\mathrm{Zn}$ ferrite by using the pulse transmission method at $1 \mathrm{MHz}$, in the temperature range $300-600 \mathrm{~K}$. The velocity was found to be slightly sample dependent at room temperature and decreased with increasing temperature, except near the Curie temperature, $T_{c}$, where a small anomaly was observed. The longitudinal attenuation $\left(\alpha_{1}\right)$ at room temperature was found to be more sample dependent. The temperature variation of ultrasonic longitudinal attenuation exhibited a broad maximum around $400 \mathrm{~K}$ and a sharp maximum just below Curie temperature $\left(T_{\mathrm{c}}\right)$. The above observations were carried out in the demagnetized state. The application of a $380 \mathrm{mT}$ magnetic field allowed us to reach the saturated state of the sample at all the measuring temperatures. The anomaly observed in the thermal variation of velocities (longitudinal and transverse) and attenuation has been qualitatively explained with the help of the temperature variation of the magneto-crystalline anisotropy constant.
\end{abstract}

Keywords. Ferrites; magnetic properties; ultrasonic velocity; attenuation; domain walls.

\section{Introduction}

There is an abundant literature on the propagation of ultrasonic waves in magnetic materials, but a few interpretations only refer to possible effects due to the domain wall (DW) (Le Craw et al 1960). It was known from the acoustic emission (AE) studies on magnetic materials that the space occupied by a DW is the location of magnetoelastic interactions and ultrasonic bursts are emitted when the DW are created or annihilated (Guyot et al 1989; Guyot and Cagan 1991). It was also found that the specific DW/lattice magneto-elastic interactions might be one of the origins of the DW relaxation. In order to understand interaction of DW with ultrasonic velocity, a detailed study of the thermal variation of ultrasonic longitudinal $\left(V_{1}\right)$ velocity, transverse $\left(V_{\mathrm{S}}\right)$ velocity and longitudinal attenuation $\left(\alpha_{1}\right)$ on a series of polycrystalline $\mathrm{Ni}-\mathrm{Zn}$ ferrites was undertaken and the results thus obtained are presented here.

\section{Experimental}

High purity polycrystalline samples were prepared by using a ceramic method (Murthy 1979). Pure (99.99\%) $\mathrm{NiO}, \mathrm{ZnO}$ and $\mathrm{Fe}_{2} \mathrm{O}_{3}$ powders with different particle sizes were used for the preparation. $\alpha-\mathrm{Fe}_{2} \mathrm{O}_{3}$ coarse particles (average diameter $0.13 \mu \mathrm{m}$ ) were synthesized by oxidation of $\mathrm{Fe}_{3} \mathrm{O}_{4}$ particles at $800^{\circ} \mathrm{C}$. Industrial grade particles of $\mathrm{Ni}$ and $\mathrm{Zn}$ oxides were used as the coarse particles with average diameters of $0.6 \mu \mathrm{m}$ and $0 \cdot 16 \mu \mathrm{m}$, respectively. Fine particles of $\mathrm{Ni}$ and $\mathrm{Zn}$ oxides were synthesized by thermal decomposition of $\mathrm{Ni}$ and $\mathrm{Zn}$ oxalate at $400^{\circ} \mathrm{C}$ in air. These powders were mixed together with wet attrition milling. Their molar ratio was adjusted to $\mathrm{Ni}_{0.46} \mathrm{Zn}_{0.54} \mathrm{Fe}_{2} \mathrm{O}_{4}$. All the dried powders were calcined at $800^{\circ} \mathrm{C}$ for $6 \mathrm{~h}$ in air and re-ground by wet ball milling for $100 \mathrm{~h}$ to form slurry. Then the powder was passed through a sleeve $(60 \mathrm{mesh})$. To this powder, $2 \mathrm{wt} \%$ poly-vinylalcohol was added as a binder. The granules were compacted at a pressure of $190 \mathrm{MPa}$ for $10 \mathrm{~min}$, into plates, rods and toroidal shaped samples. By selecting the proper combination of time of grinding and compacting pressure, the porosity and grain diameter of the samples were varied independently (Globus 1977). The specimens were heated up to $400^{\circ} \mathrm{C}$ to remove the binder and the lubricant. Finally, the samples were sintered at $1000^{\circ} \mathrm{C} /$ $50 \mathrm{~h}, 1050^{\circ} \mathrm{C} / 50 \mathrm{~h}, 1100^{\circ} \mathrm{C} / 50 \mathrm{~h}, 1150^{\circ} \mathrm{C} / 100 \mathrm{~h}$ and $1250^{\circ} \mathrm{C} /$ $100 \mathrm{~h}$ in air. The rate of heating and cooling during the sintering was $20^{\circ} \mathrm{C} / \mathrm{h}$.

The mono-phasic nature of the samples was studied with the help of X-ray analysis. Sintered density was determined by measuring the dimensions and weight. Each specimen was ground, polished by the standard metallurgical procedure, and then etched thermally at a temperature of $100-150^{\circ} \mathrm{C}$ for $30 \mathrm{~min}$. The etched sample was examined using optical microscopy. Average grain size $\left(D_{\mathrm{m}}\right)$ was measured using the relation: 


$$
D_{\mathrm{m}}=S / x^{2}-N,
$$

where $S$ is the surface of the photographed part of the sample, $x$ the linear magnification, and $N$ the number of grains in the surface $S$. The room temperature magnetic properties were obtained by recording hysteresis loops with the help of vibrating sample magnetometer (VSM).

A conventional ultrasonic pulse transmission technique was used to measure the velocities and attenuation at $1 \mathrm{MHz}$ (Papaiah 1992). The samples were inserted into a controlled temperature chamber which in turn were placed in between the pole gap of an electromagnet. This allowed us to measure the field and temperature dependence of the ultrasonic velocities and attenuation. The magnetic field was always applied parallel to the length of sample. The accuracy in the velocity and attenuation measurements is $0.01 \%$ and $0.5 \%$, respectively.

\section{Results and discussion}

It can be seen from table 1 that the sintered density reached $98.8 \%$ of the theoretical density at $1050^{\circ} \mathrm{C}$. The ultra fine particle size and relatively uniform grains are believed to be responsible for achieving this very high densification at low temperature, compared to much higher temperatures normally employed with the conventional process $\left(\sim 1300^{\circ} \mathrm{C}\right)$. We could not reach the theoretical value because, the ferrite particle being too fine to be completely dispersed in the liquid suspension and, therefore, flocculated to some extent by Van der Waals bonding. This slightly flocculated suspension resulted in some agglomerated regions distributed in the microstructure of samples. This was confirmed by microstructure. Rearrangement and differential microdensification processes could not, thus, be wholly avoided during the sintering of these slightly inhomogeneous packed compacts and therefore completely dense fired bodies were not achieved.

The microstructure of sintered specimens indicated relatively uniform grains with the porosity situated solely at the grain boundaries. The use of fine ferrite powders may be responsible for the intergranular porosity. It can be seen from table 1 that simultaneous grain growth and densification occurs in the present samples. At $1100^{\circ} \mathrm{C}$ the compact densified readily up to $99 \%$ of the theoretical maximum and grain size increased to about $5.8 \mu \mathrm{m}$. At temperatures $>1150^{\circ} \mathrm{C}$, significant grain coarsening occurred with the grain size increasing from 6.9 to $10.2 \mu \mathrm{m}$ at $1250^{\circ} \mathrm{C}$.

In the present experiment, the $\mathrm{Ni}-\mathrm{Zn}$ ferrites have densities in the range $5 \cdot 29-5 \cdot 32 \mathrm{~g} / \mathrm{cm}^{3}$. This density variation is small compared to the variation of grain size $(1 \cdot 2-10 \cdot 2 \mu \mathrm{m})$. Therefore, grain size, not density, has the dominant effect on various properties. The average value of lattice constant in the present samples is $8.416 \AA$ which is in good agreement with the literature value (Agajanian and Turk 1966; Murthy 1979).

Magnetic properties such as saturation magnetization $\left(M_{\mathrm{S}}\right)$, remanence $\left(M_{\mathrm{r}}\right)$ and coercivity $\left(H_{\mathrm{c}}\right)$ obtained from the recorded hysteresis loops are presented in table 1. As the sintered density is same for present samples, the values of $M_{\mathrm{S}}$ and $M_{\mathrm{r}}$ are also found to be nearly same. However, $H_{\mathrm{c}}$ is highly independent of the density, but dependent on the grain size of the samples and varies with the reciprocal of grain size. Globus (1977) studied the relationship between the hysteresis loop and the grain size for YIG. The experimental results show that the coercivity is inversely proportional to the average grain size, and that the remanence is independent of the grain size. Igarashi and Kazaki (1977) also indicated, through experiments and theoretical derivation, that $H$ is inversely proportional to grain size, $D_{\mathrm{m}}$. Similar result was also observed by many others in the case of $\mathrm{Ni}-\mathrm{Zn}$ and $\mathrm{Mn}-\mathrm{Zn}$ ferrites (Stopples 1980; Pyun and Baek 1985).

Table 2 gives the room temperature values of longitudinal $\left(V_{1}\right)$ and transverse $\left(V_{\mathrm{S}}\right)$ velocities along with the computed values of elastic constants; Young's $(Y)$, shear $(\mu)$, and bulk modulus $(K)$. The room temperature values of $\alpha_{1}$ are also included in table 2.

It is clear from the table that the room temperature velocities $V_{1}$ and $V_{\mathrm{S}}$ increased from $6.24 \mathrm{~km} / \mathrm{s}$ to $7.56 \mathrm{~km} / \mathrm{s}$ and $3.38 \mathrm{~km} / \mathrm{s}$ to $3.89 \mathrm{~km} / \mathrm{s}$, respectively with an increase in density. Reciprocally, the attenuation coefficient was found to decrease from 0.58 to $0.2 \mathrm{~dB} / \mathrm{cm}$. In the present samples the increase in density has increased the grain size from $1.2 \mu \mathrm{m}$ to $10 \cdot 2 \mu \mathrm{m}$. As the porosity of samples remained constant, the increase in the velocities and decrease in the attenuation may be considered due to an increase in the grain size. It can be seen from the table that the values of $Y$ and $\mu$ are also found to increase with an increase of grain size. These observations are in good agreement with results of

Table 1. Magnetic properties of $\mathrm{Ni}-\mathrm{Zn}$ ferrites at room temperature.

\begin{tabular}{llcccccc}
\hline $\begin{array}{l}\text { Sample } \\
\text { no. }\end{array}$ & $T_{\mathrm{S}}(\mathrm{C} / \mathrm{h})$ & $\begin{array}{c}\% \text { Theor. } \\
\text { density }\end{array}$ & $\begin{array}{c}\text { Grain size } \\
(\mu \mathrm{m})\end{array}$ & $\begin{array}{c}B_{\mathrm{S}} \\
(\mathrm{mT})\end{array}$ & $\begin{array}{c}H_{\mathrm{c}} \\
(\mathrm{A} / \mathrm{m})\end{array}$ & $\begin{array}{c}M_{\mathrm{r}} \\
\left(\mathrm{Am}^{-2} / \mathrm{kg}\right)\end{array}$ & $\begin{array}{c}\mu_{\mathrm{i}} \\
(1 \mathrm{MHz})\end{array}$ \\
\hline NZ-1 & $1000 / 50$ & $98 \cdot 3$ & $1 \cdot 2$ & 340 & 33 & 45 & $49 \cdot 65$ \\
NZ-2 & $1050 / 50$ & $98 \cdot 8$ & $4 \cdot 5$ & 345 & 24 & 48 & $73 \cdot 15$ \\
NZ-3 & $1100 / 50$ & $99 \cdot 0$ & $5 \cdot 8$ & 348 & 22 & 45 & $128 \cdot 55$ \\
NZ-4 & $1150 / 100$ & $99 \cdot 0$ & $6 \cdot 9$ & 350 & 21 & 45 & $225 \cdot 12$ \\
NZ-5 & $1250 / 100$ & $99 \cdot 0$ & $10 \cdot 2$ & 350 & 20 & 46 & $285 \cdot 34$ \\
\hline
\end{tabular}


Papadakis (1965). The value of Poisson's ratio $(\sigma)$, however, remains constant $(=0 \cdot 31)$ within the experimental error.

Young's modulus for $\mathrm{Ni}-\mathrm{Zn}$ ferrite of composition $\mathrm{Ni}_{0.5} \mathrm{Zn}_{0.5} \mathrm{Fe}_{2} \mathrm{O}_{4}$ has been determined by Weil et al (1951) using the resonant frequency of radial oscillations in a ring. For a specimen of density $4.5 \times 10^{4} \mathrm{~kg} / \mathrm{m}^{2}$, the value of $Y$ is given as $11.7 \times 10^{10} \mathrm{~N} / \mathrm{m}^{2}$. Van der Burgt (1953) measured the dynamic elastic constants for the $\mathrm{Ni}-\mathrm{Zn}$ ferrites by using the magnetostrictive method of excitation. He measured the $Y$ and $\mu$ on the toroids and tubular samples of diameters $\sim 2 \mathrm{~mm}$ and $4 \mathrm{~mm}$. The values of $Y$ and $\mu$ for different compositions obtained by him are $18.9 \times 10^{10} \mathrm{~N} / \mathrm{m}^{2}$ and $7.1 \times 10^{10} \mathrm{~N} / \mathrm{m}^{2}$ for $\mathrm{Ni}_{0.3} \mathrm{Zn}_{0.7} \mathrm{Fe}_{2} \mathrm{O}_{4}$; $18.4 \times 10^{10} \mathrm{~N} / \mathrm{m}^{2}$ and $6.9 \times 10^{10} \mathrm{~N} / \mathrm{m}^{2}$ for $\mathrm{Ni}_{0.5} \mathrm{Zn}_{0.5} \mathrm{Fe}_{2} \mathrm{O}_{4}$; and $18.1 \times 10^{10} \mathrm{~N} / \mathrm{m}^{2}$ and $6.6 \times 10^{10} \mathrm{~N} / \mathrm{m}^{2}$ for $\mathrm{Ni}_{0.7} \mathrm{Zn}_{0.3} \mathrm{Fe}_{2} \mathrm{O}_{4}$, respectively. Revathi and Rao (1973) measured the elastic constants of $\mathrm{Ni}_{1-X} \mathrm{Zn}_{X} \mathrm{Fe}_{2} \mathrm{O}_{4}(X=0,0 \cdot 3,0 \cdot 5,0 \cdot 3$ and $0 \cdot 1)$ by using the composite piezo-electric oscillator method. The values of $Y$ and $\mu$ obtained by them are $17.73 \times$ $10^{10} \mathrm{~N} / \mathrm{m}^{2}$ and $7.17 \times 10^{10} \mathrm{~N} / \mathrm{m}^{2}$ when $X=0,17.44 \times$ $10^{10} \mathrm{~N} / \mathrm{m}^{2}$ and $6.33 \times 10^{10} \mathrm{~N} / \mathrm{m}^{2}$ when $X=0 \cdot 3,17 \cdot 25 \times 10^{10} \mathrm{~N} /$ $\mathrm{m}^{2}$ and $6.14 \times 10^{10} \mathrm{~N} / \mathrm{m}^{2}$ when $X=0.5$, and $16.84 \times 10^{10} \mathrm{~N} / \mathrm{m}^{2}$ and $5.94 \times 10^{10} \mathrm{~N} / \mathrm{m}^{2}$ when $X=0 \cdot 7$, respectively. Murthy et al $(1978,1981)$ measured the values of $Y$ and $\mu$ for $\mathrm{Ni}-\mathrm{Zn}$ ferrites by using the composite oscillator method. The values of $Y$ and $\mu$ obtained by them for the sample with composition $\mathrm{Ni}_{0.5} \mathrm{Zn}_{0.5} \mathrm{Fe}_{2} \mathrm{O}_{4}$ are $17.42 \times 10^{10} \mathrm{~N} / \mathrm{m}^{2}$ and $6.29 \times 10^{10} \mathrm{~N} / \mathrm{m}^{2}$. We in this study obtained value of $Y$ for the polycrystalline $\mathrm{Ni}-\mathrm{Zn}$ samples which varied from $15.51 \times 10^{10} \mathrm{~N} / \mathrm{m}^{2}$ to $21.12 \times 10^{10} \mathrm{~N} / \mathrm{m}^{2}$. Similarly, the value of $\mu$ varied from $6.01 \times 10^{10} \mathrm{~N} / \mathrm{m}^{2}$ to $8.01 \times 10^{10} \mathrm{~N} / \mathrm{m}^{2}$ (table 1 ). Thus, our values are in fair agreement with that of the reported values, when the values are compared for specimens of the same or nearly the same density and composition.

Figures 1 and 2 give the thermal variation of the longitudinal and transverse velocities measured in the demagnetized state for all samples. It can be seen from the figures that the values of $V_{1}$ and $V_{\mathrm{S}}$ decreases smoothly with increasing temperature and attain a minimum at a certain temperature $\left(T_{1}\right)$ below the Curie point. Beyond this temperature the velocities show a positive temperature coefficient and attain a maximum value at a temperature $T_{2}$. With further increase of temperature both the velocities are found to decrease. It is also observed that the longitudinal velocities measured on the samples NZ-4 and NZ-5 are very close to each other and their variation

Table 2. Room temperature preparation and elastic modulus data for $\mathrm{Ni}-\mathrm{Zn}$ ferrites.

\begin{tabular}{lccccccc}
\hline $\begin{array}{l}\text { Sample } \\
\text { no. }\end{array}$ & $\begin{array}{c}V_{1} \\
(\mathrm{~m} / \mathrm{s})\end{array}$ & $\begin{array}{c}V_{\mathrm{S}} \\
(\mathrm{m} / \mathrm{s})\end{array}$ & $\begin{array}{c}\alpha_{1} \\
(\mathrm{~dB} / \mathrm{cm})\end{array}$ & $\begin{array}{c}Y \times 10^{-10} \\
\left(\mathrm{~N} / \mathrm{m}^{2}\right)\end{array}$ & $\begin{array}{c}\mu \times 10^{-10} \\
\left(\mathrm{~N} / \mathrm{m}^{2}\right)\end{array}$ & $\begin{array}{c}K \times 10^{-10} \\
\left(\mathrm{~N} / \mathrm{m}^{2}\right)\end{array}$ & $\sigma$ \\
\hline NZ-1 & 6250 & 3381 & 0.58 & 15.51 & 6.01 & 12.30 & $0 \cdot 31$ \\
NZ-2 & 6482 & 3668 & 0.55 & 18.06 & 7.17 & 12.54 & 0.31 \\
NZ-3 & 6532 & 3571 & $0 \cdot 43$ & $18 \cdot 80$ & $7 \cdot 52$ & 12.53 & 0.31 \\
NZ-4 & 7471 & 3807 & 0.33 & 20.09 & 7.52 & 19.70 & 0.31 \\
NZ-5 & 7558 & 3892 & 0.31 & 21.12 & 8.00 & 19.56 & 0.31 \\
\hline
\end{tabular}

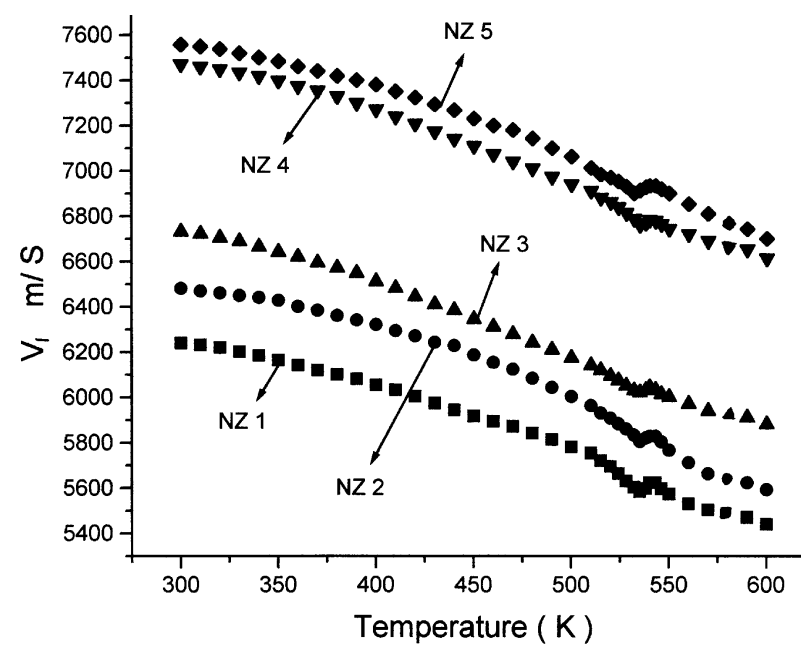

Figure 1. Thermal variation of longitudinal velocity $\left(V_{1}\right)$ for $\mathrm{Ni}-\mathrm{Zn}$ ferrites.

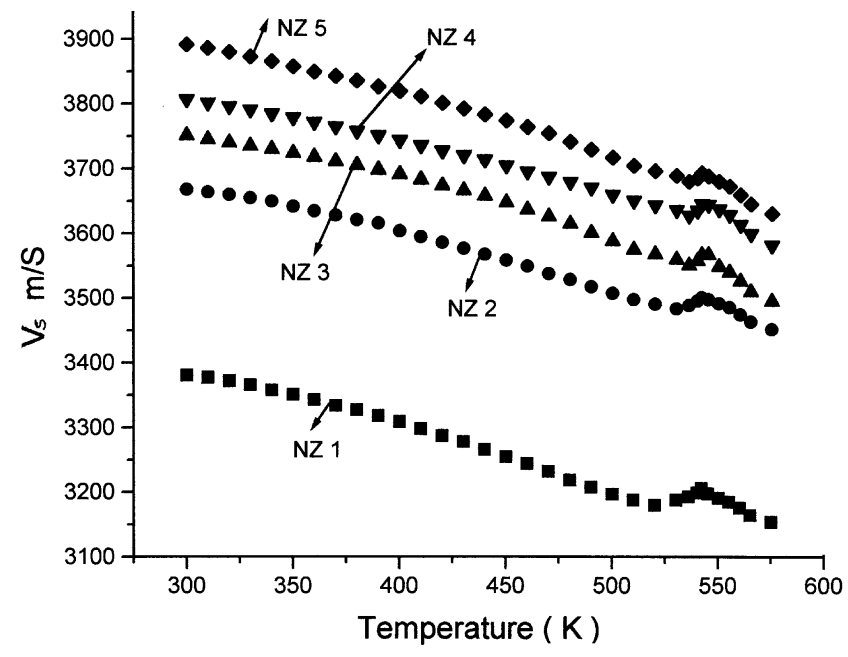

Figure 2. Thermal variation of shear velocity $\left(V_{\mathrm{s}}\right)$ for $\mathrm{Ni}-\mathrm{Zn}$ ferrites. 
is about $8.8 \%$ between $300 \mathrm{~K}$ and $T_{\mathrm{c}}$. For samples, NZ-1, NZ-2 and NZ-3, the values of $V_{1}$ are found to decrease by about $10 \%$ between $300 \mathrm{~K}$ and $T_{\mathrm{c}}$. In all these samples anomalous behaviour occurs in between $525 \mathrm{~K}$ and $540 \mathrm{~K}$. The thermal variation of $V_{\mathrm{S}}$ for all the samples is found to be similar and the variation is about $5 \%$ between $300 \mathrm{~K}$ and $T_{\mathrm{c}}$. A less $(535$ to $540 \mathrm{~K})$ pronounced increase of $V_{\mathrm{S}}$ with temperature is observed near the Curie point. No hysteresis has been observed during cooling.

At a given temperature velocity decreases when the mean grain size increases; this tendency is maintained all over the investigated temperature range. The decrease of $V_{1}$ and $V_{\mathrm{S}}$ with temperature is mainly due to the softening of the material.

Murthy and Rao $(1979,1983)$ have observed a similar anomalous behaviour in the thermal variation of longitudinal and shear velocities for $\mathrm{Ni}-\mathrm{Zn}, \mathrm{Co}-\mathrm{Zn}$ and $\mathrm{Mn}-\mathrm{Zn}$ ferrites in the vicinity of the Curie temperature. Novikov and Stel'mashenke (1967) and Kawai and Ogawa (1978) in the cases of $\mathrm{NiCaMn}$ and $\mathrm{Mn}$ ferrites also have observed, respectively a similar anomalous variation of Young's modulus near the Curie temperature.

The anomalous behaviour of ferrites can be explained qualitatively with help of the temperature variation of the magneto-crystalline anisotropy constant $\left(k_{1}\right)$. The temperature variation of $k_{1}$ was measured on the brother samples and found that $k_{1}$ becomes zero just below the Curie temperature i.e. at $523 \mathrm{~K}$ (Papaiah 1992). The measurements of initial permeability vs temperature on the brother sample, has shown that the Curie temperature of the present samples is $538 \mathrm{~K}$.

As can be seen from figures 1 and 2 , the $V_{1}$ and $V_{\mathrm{S}}$ for present samples have reached a minimum value at temperature $525 \mathrm{~K}\left(T_{1}\right)$, while $k_{1}$ becomes zero at $523 \mathrm{~K}$. Similarly, the $V_{1}$ and $V_{\mathrm{S}}$ attain a maximum value at a temperature $540 \mathrm{~K}\left(T_{2}\right)$, while the Curie point of samples

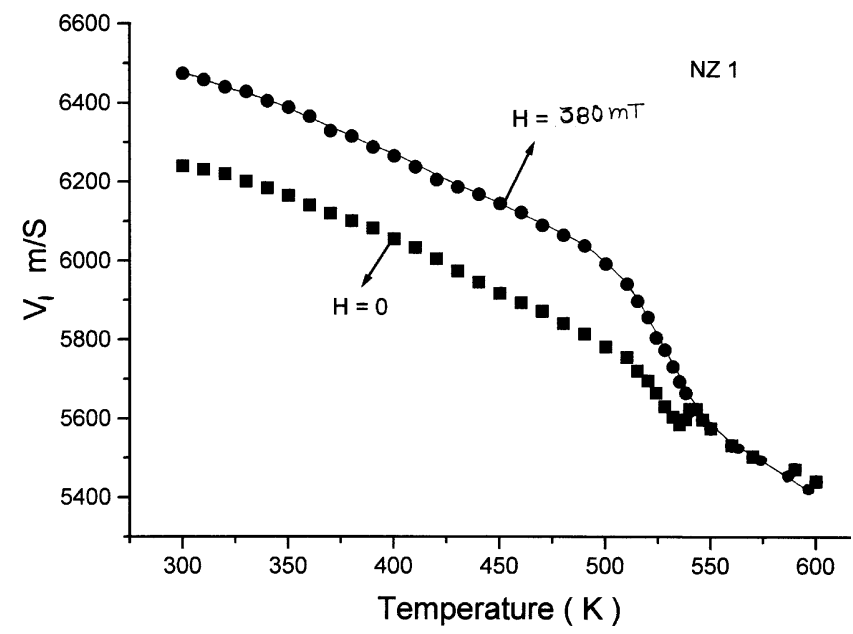

Figure 3. Thermal and magnetic field variations of $V_{1}$ for NZ-1 ferrites. under investigation is $538 \mathrm{~K}$. Thus, the minimum $\left(T_{1}\right)$ and maximum $\left(T_{2}\right)$ temperatures of $V_{1}$ and $V_{\mathrm{S}}$ vs temperature plots coincides with temperatures of $k_{1}=0$ and the Curie temperature, respectively.

The magneto-crystalline anisotropy constant can be considered as a measure of the magnetic energy barrier to the movement of domain walls in the magnetic materials. As such, domains will be free to move at a temperature at which $k_{1}=0$, the substance undergoes a maximum strain for a given stress, in other words the $V_{1}$ and $V_{\mathrm{S}}$ increases till the Curie temperature is reached. Beyond the Curie temperature, both the velocities show a decrease with an increase of temperature, since at $T_{\mathrm{c}}$ the ferrite loses its spontaneous magnetization and becomes paramagnetic.

In figures 3 and 4 , for the sample NZ-1, we present the temperature dependence of $V_{1}$ and $V_{\mathrm{S}}$ measured both in $H=0$ and with $H=380 \mathrm{mT}$; this field was found to be high enough to saturate the sample at any of the measuring temperatures. In saturated state $V_{1}$ (or $V_{\mathrm{S}}$ ) is slightly higher than in the demagnetized state, except above $T_{\mathrm{c}}$, where both the values are identical, as expected. When the sample is subjected to magnetic field, it is observed that the minimum of velocity-temperature curve is shifted to the low temperature side and becomes shallow. As the magnetic field increased further the minimum continued to shift to the low temperature side becoming more and more shallow. Finally the dip disappeared when the magnetic field was equal to saturation field of the sample. This was because at the saturation value the domain wall movement was frozen completely.

The magnetic contribution to the velocity variations with temperature can be considered as a 'second order effect', superimposed on the purely mechanical effects; it is more pronounced for the large grain size samples. The magnetic contribution $\mathrm{d} V_{1}$ or $\mathrm{d} V_{\mathrm{S}}$ defined as the difference between the velocity in the saturated and demagnetized states is, respectively given by: $\mathrm{d} V_{1}=V_{1}(H=380 \mathrm{mT})$

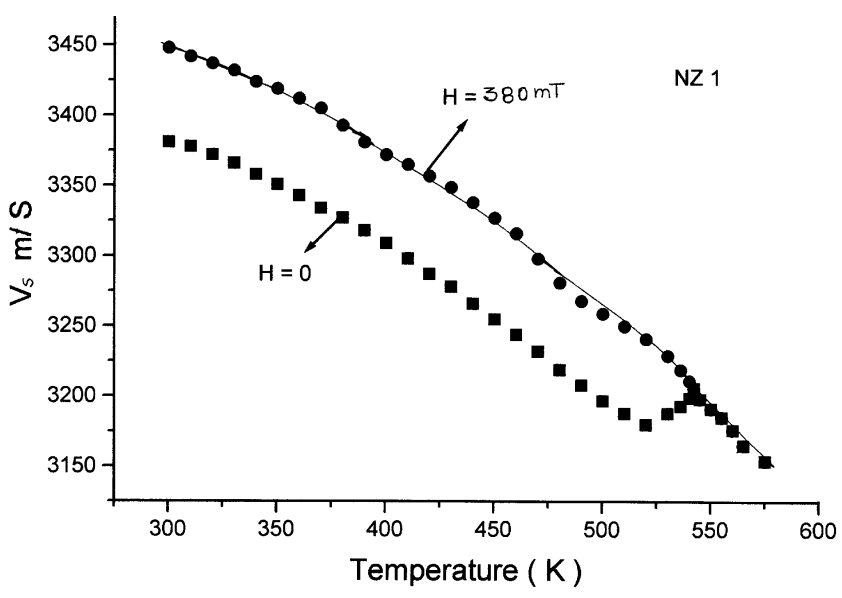

Figure 4. Thermal and magnetic field variations of $V_{\mathrm{s}}$ for NZ-1 ferrites. 
$-V_{1}(H=0)$ and $\mathrm{d} V_{\mathrm{S}}=V_{\mathrm{S}}(H=380 \mathrm{mT})-(H=0)$, and are not more than $4 \%$ and $2 \%$ of the total velocity and varies like the temperature variation of saturation magnetization $\left(M_{\mathrm{S}}\right)$ i.e. decreases with an increase of temperature and finally becomes zero at Curie temperature. Similar variation of $V_{1}$ on temperature and magnetic field was observed for all the other samples.

In monodomain state the values of $V_{1}$ are found to decrease continuously with increasing temperature. This variation of $V_{1}$ with temperature $(T)$ can be represented by an exponential equation (Vasudev 1995):

$$
V_{\mathrm{T}}=V_{0}-B T \exp \left(T_{0} / T\right),
$$

where $V_{0}, B$ and $T$ are constants. The experimental data have been made to fit with above equation using the standard least-squares method with the help of computer. The values of constants obtained for NZ-1 sample are: $V_{0}=6625 \mathrm{~m} / \mathrm{S}, B=3.705 \times 10^{-4} \mathrm{k} / \mathrm{S} \mathrm{K}$ and $T_{0}=624 \mathrm{~K}$. On the other hand, a linear equation of the form

$$
V_{\mathrm{S}}=V_{0}-b T
$$

(where $V_{0}$ and $b$ are constants) is used to describe the variation of $V_{\mathrm{S}}$ with temperature. The constants in the above equation for NZ-1 are $V_{0}=3500 \mathrm{~m} / \mathrm{sec}$ and $b=0 \cdot 588$.

In figures 3 and 4 centres of the dots correspond to the experimental points, while the solid line represents the curves drawn on the basis of above equations. The experimental points are found to lie on the solid line with a maximum deviation of $0.5 \%$.

Figure 5 gives the thermal variation of $\alpha_{1}$ measured at zero fields for all samples. It can be seen from the figure that the sample shows a small maximum around $400 \mathrm{~K}$ and broad maximum just below the Curie temperature. The rapid increase of $\alpha_{1}$ has been extended over $10 \mathrm{~K}$

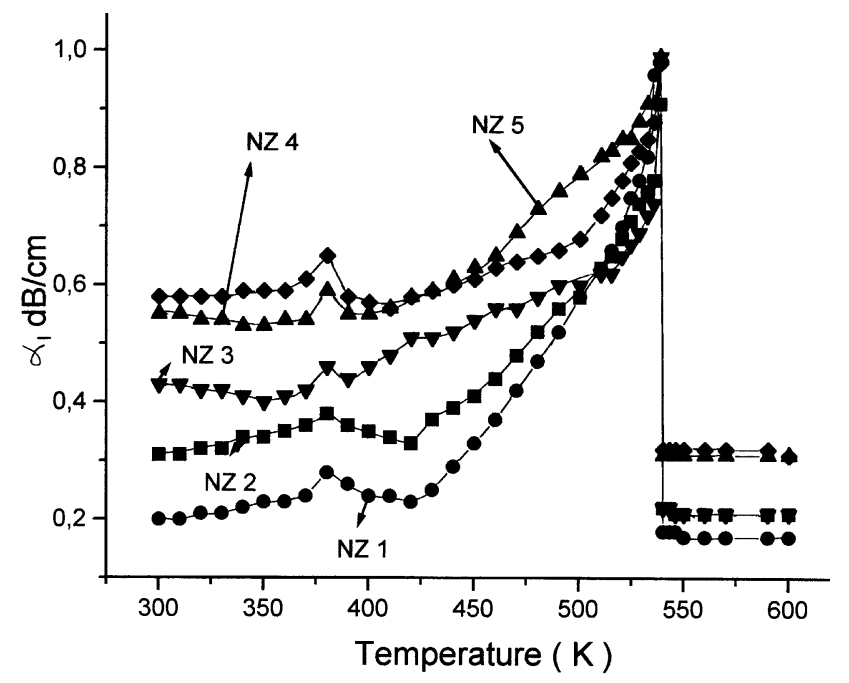

Figure 5. Thermal variation of longitudinal attenuation $\left(\alpha_{1}\right)$ for $\mathrm{Ni}-\mathrm{Zn}$ ferrites. below $T_{\mathrm{c}}$ : the very sharp decrease of $\alpha_{1}$ from about $0.97 \mathrm{~dB} / \mathrm{cm}$ down to $0.2 \mathrm{~dB} / \mathrm{cm}$ is accomplished in less than $2 \mathrm{~K}$. This abrupt change is the signature of the high chemical homogeneity of our samples.

In figure 6 , for the sample NZ-1, we present the temperature dependence of $\alpha_{1}$ measured both in $H=0$ and with $H=380 \mathrm{mT}$. The value of $\alpha_{1}$ in the saturated state is almost temperature independent $(=0.17 \mathrm{~dB} / \mathrm{cm})$, and is equal to the zero field value above $T_{\mathrm{c}}$, also as expected. Similar variation of $\alpha_{1}$ on temperature and magnetic field was also observed for all the other samples.

In all the samples under investigation, it is observed that the temperature corresponding to the peak in the attenuation vs temperature curve is near about the temperature at which both the velocities show maximum value. As the ultrasonic attenuation is the complementary phenomena of the elastic behaviour, as such, the peak observed in $\alpha$ vs $T$ curve can be attributed to the $k_{1}=0$.

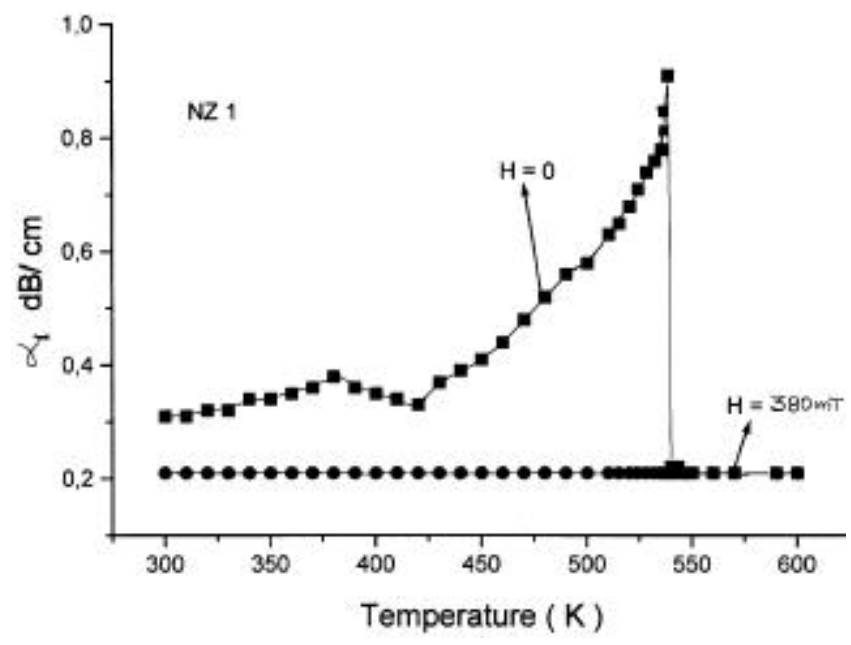

Figure 6. Thermal and magnetic field variation of $\alpha_{1}$ for NZ-1 ferrites.

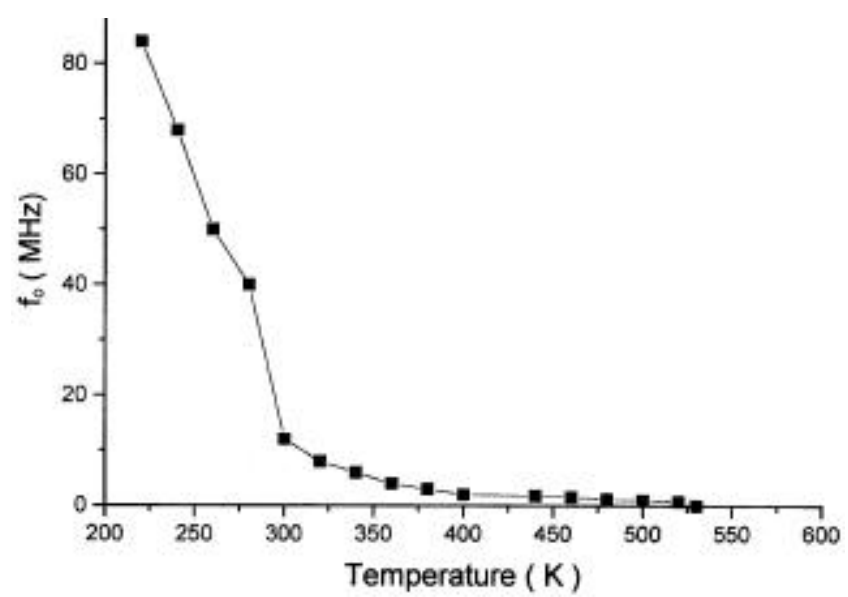

Figure 7. A plot of $f_{0}$ vs temperature $(T)$. 


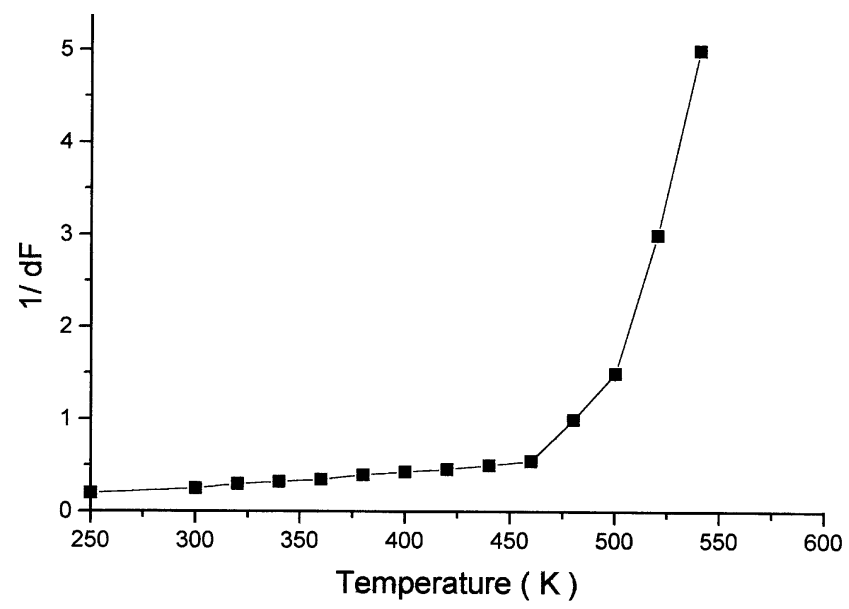

Figure 8. Thermal dependence of relative frequency distance $(1 / \mathrm{d} F)$.

The effects of microstructure are well marked on the attenuation but they are not as dominant as for the velocity. It can be seen from figures 7 and 8 , the microstructure contribution to $\alpha_{1}$ is of the order of $95 \%$ of the total (when compared to more than 30 to $40 \%$ on $V_{1}$ ). The substantial magnetic contribution to $\alpha_{1}$ seems to result from two contributions: an electronic diffusion related magnetoelastic interaction in the $400 \mathrm{~K}$ region and interaction of ultrasonic waves with the domain walls in the vicinity of $T_{\mathrm{c}}$. We know that the ferrites exhibit magnetic after-effects due to small deviations from the stoichiometry, and the relaxation time of which falls in the microsecond range above room temperature; consequently a $1 \mathrm{MHz}$ ultrasonic wave ( $1 \mu \mathrm{s}$ period) can inducethrough the magnetoelastic coupling-spin rotations or domain wall movements, which leads to electronic migrations: this can explain the relative maximum of $\alpha_{1}$ observed around $400 \mathrm{~K}$.

An initial permeability (Guyot et al 1989) studies were made on same sample and found that the relaxation frequency $\left(f_{\mathrm{DW}}\right)$ of the domain walls decreased down to $\mathrm{MHz}$ range before $T_{\mathrm{c}}$ (figure 7 ) with an increase of temperature. Figure 8 gives a plot of relative frequency distance $(\mathrm{d} F)$ vs temperature and is given by

$$
1 / \mathrm{d} F=F_{\mathrm{US}} / F_{\mathrm{DW}}-F_{\mathrm{US}}=1 / F_{\mathrm{DW}}-1,
$$

where $F_{\mathrm{US}}$ is the relaxation frequency of the ultrasonic waves and the same was obtained from the frequency variation attenuation (Papaiah 1992). The quantity $(\mathrm{d} F)$ has a non-negligible value only very close to $T_{\mathrm{c}}$ and similar sharp temperature dependence as that of $\alpha_{1}$ close to $T_{\mathrm{c}}$. In other words, the absorption of ultrasonic waves and the relaxation of domain wall in the same frequency range are mirror effects: the domain wall can couple to absorb adapted frequency of ultrasonic waves or relax through the emission of elastic waves. Further, detailed studies are in progress on different ferromagnetic oxides to understand this problem.

\section{Acknowledgements}

The author is thankful to UGC, New Delhi for a Research Award and to DST, New Delhi, for financial assistance to carry out this work.

\section{References}

Agajanian A H and Turk H L 1966 J. Am. Ceram. Soc. 15 459

Gallagher P K, Gyorgy E M and Johnson D W 1978 Am. Ceram. Soc. Bull. 57812

Globus A 1977 Proc. J. Phys. Colloq. 38 C1

Globus A and Duplex P 1968 J. Appl. Phys. 39727

Guyot M T, Merceron M T and Cagan V 1989 Proc. ICF5, (New Delhi: Oxford Pub.) p. 205

Guyot M and Cagan V 1991 J. Magn. Magn. Mater. 101256

Igarashi H and Kazaki O J 1977 Am. Ceram. Soc. 6051

Kawai Y and Ogawa T 1978 J. Phys. Soc. Jap. 451830

Landau L D and Lifshitz E H 1959 Statistical physics (London: Pergamon Press) p. 398

Le Craw R C and Comstock R L 1960 in Physical acoustics (ed.) W P Mason (New York: Academic Press Inc.) Vol. IIIB, p. 127

Murthy S R 1979 Elastic behaviour, internal friction and magnetostriction studies on polycrystalline NiZn and CoZn ferrites in the vicinity of Curie temperature, Ph.D. Thesis, Osmania University, Hyderabad

Murthy S R and Rao T S 1979 J. Less Common Metals 6519

Murthy S R and Rao T S 1981 J. Pure \& Appl. Ultra. 368

Murthy S R and Rao T S 1983 J. Acoust. Soc. India 1136

Murthy S R, Revathi B and Rao T S 1978 J. Less Common Metals $\mathbf{5 7} 29$

Novikov E N and Stel'mashenke M A 1967 Izv. Vuz. Fiz. (USSR) 11127

Papaiah P 1992 Elastic behaviour in polycrystalline YIG, Ph.D. Thesis, Osmania University, Hyderabad

Pyun S I and Baek J T 1985 Am. Ceram. Soc. Bull. 64602

Papadakis E P 1965 J. Acoust. Soc. Am. 42703

Revathi B and Rao T S 1973 J. Acoust. Soc. India 171

Showry B 1994 A study of initial permeability and magnetic properties of polycrystalline Mn-Zn Ferrites, Ph.D. Thesis, Osmania University, Hyderabad

Stopples D 1980 J. Appl. Phys. 512789

Van Der Burgt C M 1953 Philips Res. Rep. 891

Vasudev B 1995 Elastic and magnetic properties of polycrystalline $M n-Z n$ ferrites, Ph.D. Thesis, Osmania University, Hyderabad

Weil L and Bochirol L 1951 C.R. Acad. Sci. 2321807 